\title{
Good Questions 14: IS FEEDING WITH INFANT FORMULA MUCH WORSE THAN BREASTFEEDING?
}

\author{
By George Kent ${ }^{1}$
}

\section{ABSTRACT}

Is infant feeding with formula much worse than breastfeeding? It's complicated, so this essay explores the evidence and ways to think about it.

There is a clear global consensus that in any population, feeding with infant formula is not as good as breastfeeding for infants' health and also for their mothers' health. Infant formula manufacturers agree. Nevertheless, there is an ongoing debate about when feeding with infant formula might be acceptable.

Undoubtedly, compliance with the global recommendations for optimum breastfeeding is low partly because many new parents and policymakers believe there is little difference between the health impacts of breastfeeding and feeding with formula. It is important to consider not only the ranking of alternative methods of infant feeding but also the degree of difference between them. Is the difference small and unimportant or substantial and important to consider when choosing among the options? There should be an orderly way to take account of not only the relevant scientific knowledge, but also parents' views and circumstances related to infant feeding.

KEYWORDS: infant and young child feeding, breastfeeding, infant formula, human milk

\section{OPTIMUM INFANT FEEDING}

There is widespread agreement that feeding with infant formula is worse for infants' and mothers' health than breastfeeding. For optimal breastfeeding, the World Health Organization (WHO) and the United Nations Children's Fund (UNICEF) recommend:

- $\quad$ early initiation of breastfeeding within 1 hour of birth;

- exclusive breastfeeding for the first 6 months of life; and

- introduction of nutritionally-adequate and safe complementary (solid) foods at 6 months together with continued breastfeeding up to 2 years of age or beyond (WHO 2017).

\footnotetext{
${ }^{1}$ George Kent, Deputy Editor of World Nutrition, is also its Curator of Good Questions. This is the fourteenth in the series. He is Professor Emeritus (Political Science) with the University of Hawaii, and an Adjunct Professor with Saybrook University in California and also with the University of Sydney in Australia. He can be reached at kent@hawaii.edu
} 
The World Breastfeeding Trends Initiative reports on breastfeeding practices and support services in most countries (Gupta 2020; also see WBTi 2019; Gupta and Suri 2016; Gupta et al. 2018). The Global Breastfeeding Collective provides country-by-country data (WHO 2019). UNICEF summarizes the pattern:

Analysis of data on feeding practices among infants and young children highlights the need for accelerated programming in this area. Globally, only 44 per cent of newborns are put to the breast within the first hour of birth, and only 2 in 5 infants less than 6 months of age are exclusively breastfed. The World Health Organization (WHO) recommends that breastfeeding continues until age 2 and beyond, yet less than two in three young children aged 12-23 months are benefitting from it.

Global estimates for feeding of children aged 6 months to 2 years indicate substantial room for improvement. A little more than two thirds of 6-8 montholds are receiving any solid food at all, and when considering measures of diet quantity and quality, the rates are much lower: only 1 in 2 receive a minimum meal frequency and less than 1 in 3 a minimum diet diversity. (UNICEF 2019a)

The patterns are different in different places:

Levels of recommended feeding practices vary widely among regions. The share of infants that are breastfed within one hour of birth ranges from around 40 per cent in West and Central Africa and South Asia to about 65 per cent in Eastern and Southern Africa. In terms of continued breastfeeding among children 12-23 months, the range between regions is wide: the prevalence of continued breastfeeding at 12-23 months in South Asia is nearly twice as high than Latin America \& the Caribbean. Wide variations also exist for minimum diet diversity. Compared to 3 in 5 children 6-23 months of age in Latin America \& the Caribbean, only 1 in 5 children in South Asia receive foods from the minimum number of food groups. (UNICEF 2019a; also see Bartick et al. 2017)

There has been widespread concern about this noncompliance with the recommendations in academic journals and the popular press (Aubusson 2017; Bartick et al. 2013, Bartick et al. 2016, Bartick et al. 2017; Horii et al. 2016; Horii et al. 2017; Joseph and Earland 2019; Joshi et al. 2014; Lauer et al. 2006; Morrell 2017; Obinna 2017; Ogbo, Agho, and Page 2015; Ogbo et al. 2019; Paynter 2017; Rujumba et al. 2020; Woldeamanuel 2020). The reports on rates of compliance with the WHO-UNICEF recommendations are not always comparable because of the diversity of research methods and variations in what is counted as breastfeeding (Binns and Lee 2019; Greiner 2014), but there is no doubt that the compliance levels are low.

\section{VARIETIES OF NONCOMPLIANCE}

Failure to comply with the WHO/UNICEF recommendations for optimum breastfeeding occurs in various ways for various reasons and with various health impacts (Archan et al. 2011). Initiating breastfeeding just a bit over an hour after birth is not as big a problem as long-delayed 
initiation or never initiating breastfeeding. Starting other foods soon after birth is more problematic than doing it later (Smith and Becker 2016). The early introduction of other foods tends to displace breastfeeding, often resulting in worse health outcomes (Kramer and Kakuma 2002). In many cases the failure to continue exclusive breastfeeding is due not to the introduction of infant formula but to the introduction of other foods or other questionable practices (Jama et al. 2017; Joseph and Earland 2019).

High infant mortality is sometimes assumed to be due to the use of infant formula, but there are other causes. An article in The Lancet said, "The scaling up of breastfeeding to a near universal level could prevent 823000 annual deaths in children younger than 5 years" (Victora et al. 2016). One journalist claimed the article said, "more than 800,000 formula-fed-infants who die each year could be saved by breastfeeding" (Brink 2018). It did not say that. Many of those deaths would be due to suboptimal breastfeeding practices that did not involve the use of infant formula. Only some fraction of the deaths should be attributed specifically to feeding with infant formula. The impacts of inferior infant feeding practices on infant mortality and morbidity in low-income countries have been known for decades, well before the widespread use of infant formula (Mata 1978).

The high mortality rates associated with the use of infant formula in its early days was partly due to what can be described as suboptimal formula feeding practices such as mixing low quality formula powder with low quality water and not holding the infant closely during feeding. Both breastfeeding and formula feeding can be done well or done badly.

There is a need for careful comparisons of health impacts of different feeding practices because there is a large-scale global transition in infant feeding practices underway, largely due to the vigorous promotion of infant formula worldwide (Baker et al. 2016; Caron 2018; IBFAN 2020; Kent 2015; Kent 2017b; IBFAN 2020; Li et al. 2021; McFadden et al. 2016; Save the Children 2018; Vinje et al).

\section{RANKING IS TOO SIMPLE}

When comparing alternative methods of feeding infants, it is important to go beyond placing them into rank order regarding the likely health impacts (best, second best, third best, etc.) to also estimate the degree of difference. Doing this opens us to the question of whether feeding with infant formula is extremely worse than optimal breastfeeding for infants, with a wide gap between them, and thus generally unacceptable, or only slightly worse, and therefore acceptable - or somewhere in between. There is no clear consensus on the degree of difference. The answer depends on local circumstances. The health risks of feeding with formula are far higher in low-income places, especially where the water is not clean (Anttila-Hughes et al. 2018; Chang 2019; Walters, Phan, and Mathisen 2019; UNICEF 2019b).

There is a need for systematic research on the degree of difference in health impacts of different methods of infant feeding. There is no easy way to measure the difference. Some studies are not clear about what is being compared with what, on what dimensions. Health is multidimensional. One document showed 21 different ways in which the feeding method can affect the health of 
infants and their mothers (WABA 2012; also see Binn and Lee 2019, Table 4; Ip et al. 2007; Packard 1982).

Research ethics limits the kinds of randomized controlled trials that can be done. However, there are good potentials for doing observational studies using research methods that are common in epidemiological studies. For example, studies could compare the frequency and types of infant health problems in a country's population before and after the start of widespread use of infant formula.

Discussions of methods of infant feeding often refer to the benefits of breastfeeding. However, breastfeeding should be viewed as the gold standard against which all other infant feeding methods are compared (Wiessinger 1996). More precisely, optimum breastfeeding is the gold standard. Recognizing optimum breastfeeding as the gold standard is important because claims about the benefits of new types of infant formula are regularly based on comparisons with existing types, not comparisons with the gold standard.

No matter what the scientific findings regarding health outcomes might be for any particular circumstances, there is always a subjective component in their interpretation. To illustrate, it has been estimated that there are about 700 excess infant deaths in the US each year associated with suboptimal breastfeeding (Bartick et al. 2016). Should that be viewed as alarming and requiring immediate attention from government policymakers? Or is it just something to be accepted as normal, just as we now accept some number of fatal auto collisions as normal? People can agree that a particular scientific finding is accurate but still disagree on whether it should be quietly accepted or viewed as a cause for alarm and urgent action. Those disagreements need to be addressed in order to design sensible policies related to infant feeding.

It is important to assess and discuss the health impacts on infants and their mothers of different methods of infant feeding. If there is little difference, considerations other than health impacts are likely to carry more weight when comparing the feeding options. The option that is second best in relation to health impacts could become the first choice because of other considerations. When breastfeeding is impossible or extremely suboptimal and there are no other options such as wet nursing or banked human milk, well-managed feeding with formula is a sensible choice. Women who have difficulties with breastfeeding should get every type of support to help them get over those breastfeeding difficulties, including paid leave from their workplaces (Hausman 2008).

All this makes it difficult to deal with statements like this from defenders of feeding with formula:

The health benefits of breastfeeding tend to be presented as overwhelming, and imply that formula feeding will cause health problems. But the evidence shows a far less drastic difference between breastfed and formula-fed babies. (BPAS 2017)

How should we, individually or collectively, decide what is a "drastic difference"? At the very least, we should find a way to see it. Londoners are told they must "mind the gap" between trains 
and station platforms in order to judge the risks. We need to somehow see the difference in the health impacts of different methods of feeding infants. There is a need for research that tells us not only that there is a difference but also the degree of difference.

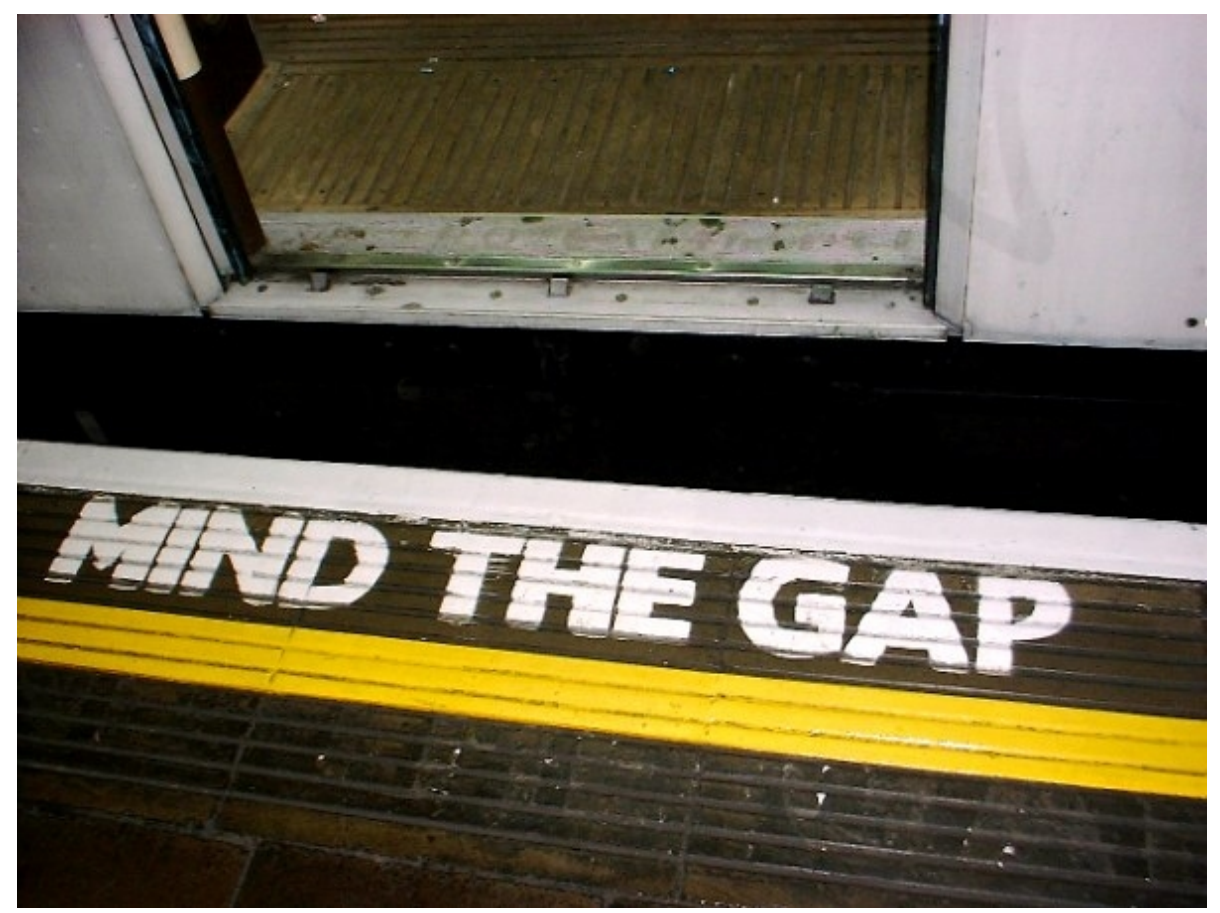

\section{https://de.wikipedia.org/wiki/Datei:London_underground_mind the gap.jpg}

Little attention has been given to the ways in which considerations other than health outcomes might affect feeding choices, wisely or unwisely (Acta Pediatrica 2015). The size of the gap matters, but it remains complex and difficult to measure. And if it is measured, what should we do with that information? How should we "mind the gap"?

There are many issues apart from health that can be taken into account when comparing different feeding methods. To some people, it is important to know whether the product is kosher or halal, or made with genetically modified organisms, or whether the manufacturing process exploits workers or harms the environment. The price of formula is important for some families and not others (Rothstein et al. 2021). There is no easy way to combine health and other considerations into simple scores that would make it easier to compare the degree to which one feeding method is better or worse than others in any individual case. Discussions about which feeding method is better for a population viewed as a whole typically center on the health impacts on the infant, but they should also consider other factors in a systematic way. Currently there is no widely accepted way of doing that.

The question of whether the difference is small or substantial is important in many contexts. When a new additive to infant formula is claimed to produce some type of benefit, is that benefit substantial? Is it big enough to justify paying a higher price for the new product? The question applies to all sorts of food additives, not just those in foods for infants and young children. There 
might be some evidence of benefits, but those benefits might be very thin (Kent 2013; Munblit et al. 2020).

Claims about the benefits of a new additive to infant formula can be very misleading, as illustrated in the claims about the addition of fatty acids to formula:

Using newer versions of the additive might have better health effects than older versions, and thus bring the product somewhat closer to the performance of breastfeeding. However, claiming that any infant formula with the fatty acid is "closest to human milk" or "as close as possible to human milk" is not the same as saying it is close to human milk. The claim may be misleading if the difference between "closer to" and "close to" escapes people's notice. (Kent 2014)

The size of the gap is especially important when parents feed their infants in ways that others judge to be seriously dangerous. Some critics of formula feel parents should be allowed to purchase formula only with a prescription from a doctor. It is usually assumed that parents get to decide how their infants should be fed, but if they go far outside the range of acceptability, that right might be taken from them. If it is discovered that infants are fed with tea or overdiluted formula, or wine, the infant might be taken away by government agents in what they view as a rescue mission. There have been legal cases in which mothers diagnosed with HIV/AIDS were told their infants would be taken from them if they breastfed their infants. When and how should parents' right to decide how to feed their infants be overridden? Who gets to decide when the gap is just too wide? On what basis? Through what procedure? I have discussed these issues elsewhere (Kent 2005).

\section{SITUATION-SENSITIVE GUIDANCE}

The analysis that was used as the basis for WHO's global recommendations acknowledged, “. . . infants should still be managed individually so that insufficient growth or other adverse outcomes are not ignored and appropriate interventions are provided" (Kramer and Kakuma 2002, 2, 20).

The guidance provided by health care workers at the local level should tailored to consider the needs and views of individual parents, and not limited to the recommendations provided by groups of experts at the global level. The localization of guidance means that local health care workers should advise parents in making their infant feeding decisions as they should when advising them regarding medications, taking the parents' views and circumstances into account.

Many critics of formula manufacturers agree that "milk formula has a positive role to play in the right conditions" (Save the Children 2018, v). Breastfeeding should be recommended in most cases, but there are conditions under which it makes sense to use infant formula and conditions under which it makes sense to use human milk from women other than the birth mother. In reviewing local circumstances, attention should be given to the availability of human milk through milk banks (Israel-Ballard et al. 2019; Kent 2017a) and wet-nurses (Lowen 2020). There may be options other than breastfeeding and formula. 
In The Dance of Nurture: Negotiating Infant Feeding, Penny Van Esterik and Richard O'Connor suggest that infant feeding should be understood as part of the broader context of nurturing. They argue, "Interventions that ignore biocultural nurturing practices are bound to fail, and fail they have" (Van Esterik and O'Connor 2017, 160). They are troubled by an approach that "works on the assumption that there is one correct way to feed an infant, without negotiation or adjustment for individual differences" (161). "Infant-feeding choices are always negotiated, always a tradeoff between what is best for mothers and infants, and what is feasible in the context of people's everyday lives" (169).

They highlight the roles of local agencies:

Local NGOs and health clinics have to reframe WHO/UNICEF documents and guidelines to fit local circumstances. Relations between mastering nurture and negotiating nurture occur at the local level, as UN documents are translated into practices recognizable in local regimens, ideally to become embedded in social practice, local habitus. UN documents and guidelines are also used by policy makers to guide national policy, but it is national policy makers who negotiate the challenge of translation, not the UN. (Van Esterik and O'Connor 2017, 188)

Local nongovernmental organizations and health clinics should work with national government agencies to interpret and adapt the global recommendations. The human rights system provides a model. Global human rights treaties set out the basic principles and call for national commitments to those principles through the ratification process. The details regarding local interpretation and implementation are worked out in national law, showing how those principles will be upheld locally. That law should be designed in collaboration with local sub-national governments and communities.

Some people seem to think the global recommendations on infant feeding should be obeyed unconditionally because they come from experts, but those experts don't want or expect unquestioning compliance by silent parents. A systematic approach to addressing local concerns has been suggested to support decision making in the context of COVID-19:

It proposes a structure and rationale to guide the process that includes (1) discussing with parents evidence-based information and the different options to feed and care for an infant and young child in the context of the pandemic as well as their potential benefits, risks and scientific uncertainties; (2) helping parents to recognize the sensitive nature of the decisions and to clarify the value they place on the different options to feed and care for their infant or young child; and (3) providing guidance and support needed to make and implement their decisions. A shared decision-making process will help parents navigate complex feeding and care decisions for their infant or young child; and (3) providing guidance and support needed to make and implement their decisions. A shared decision-making process will help parents navigate complex feeding and care decisions for their child as we face the different stages of the COVID-19 pandemic. (Haiek et al. 2021, 1) 
This shared decision-making approach would use "a form of nondirective counselling where the health care provider and patient come together as experts, in clinical evidence and lived experience respectively." (Haiek et al. 2021,3) It could be applied in many different situations, not just those involving concerns about COVID-19.

In updating their recommendations on feeding infant and young children, WHO now calls for consideration of not only the benefits and harms of particular methods of feeding, but also "values and preferences of individuals and populations affected by the recommendation" (WHO $2021,4)$. In this way, they call for the empowerment of parents by engaging them in discussion with their health care providers, saying what is important to them.

A key element of the discussion would involve highlighting "tradeoffs" that require judgments about whether it is worthwhile to give up some sort of benefit to gain another. Both evidence and beliefs about these matters should be recognized. There is a need for better research on health and other impacts and different methods of infant feeding, and for better ways of presenting the evidence in user-friendly ways. There is also a need for better engagement with parents to support them in making well-informed choices. 


\section{REFERENCES}

Acta Pediatrica. 22015. Special Issue: Impact of Breastfeeding on Maternal and Child Health. Acta Pediatrica. 104(S467):1-134. https://onlinelibrary.wiley.com/toc/16512227/2015/104/S467

Anttila-Hughes, Jessie K., Lia C.H. Fernald, Paul J. Gertler, Patrick Krause, and Bruce Wydick. 2018. Mortality from Nestlé's Marketing of Infant Formula in Low and Middle-Income Countries. Cambridge Massachusetts: National Bureau of Economic Research. NBER. Working Paper No. 24452. https://www.nber.org/papers/w24452

Archan, Marjorie, Deborah Davis, and Maralyn Foureur, .2011. "The Decision not to Initiate Breastfeeding--Women's Reasons, Attitudes and Influencing Factors--a Review of the Literature." Breastfeeding Review. 19(2):9-17. https://www.academia.edu/20595904/The decision not to initiate breastfeeding-womens reasons attitudes and influencing factors-a review of the literature? email_work card=minimal-title

Aubusson, Kate. 2017. Low Breastfeeding Rates and Formula Marketing Targeted by World Health Organization Western Pacific Delegates." The Sydney Morning Herald. October 10. http://www.smh.com.au/national/health/low-breastfeeding-rates-and-formulamarketing-targeted-by-world-health-organisation-western-pacific-delegates-20171010gyy151.html

Baker, Phillip, Julie Patricia Smith, Libby Salmon, Sharon Friel, George Kent, Alessandro Iellemo, Jai Prakash Dadhich, and Mary J. Renfrew. 2016. "Global Trends and Patterns of Commercial Milk-based Formula Sales: Is an Unprecedented Infant and Young Child Feeding Transition Underway?" Public Health Nutrition. 19(14):2540-2550. doi: $10.1017 /$ S1368980016001117

Bartick, Melissa C., Alison M. Stuebe, Eleanor Bimla Schwarz, Christine Luongo, Arnold G. Reinhold, and Michael E. Foster. 2013. "Cost Analysis of Maternal Disease Associated with Suboptimal Breastfeeding." Obstetrics \& Gynecology. 122(1):111-119. doi: 10.1097/AOG.0b013e318297a047

Bartick, Melissa C., Eleanor Bimla Schwarz, Brittany D. Green, Briana J. Jegier, Arnold G. Reinhold, Tarah T. Colaizy, Debra L. Bogen, Andrew J. Schaefer, and Alison M. Stuebe. 2016. "Suboptimal Breastfeeding in the United States: Maternal and Pediatric Health Outcomes and Costs.” Maternal \& Child Nutrition. 13(1):e12366 https://doi.org/10.1111/mcn.12366

Bartick Melissa C., Briana J. Jegier, Brittany D. Green, Eleanor Bimla Schwarz, Arnold G. Reinhold, and Alison M. Stuebe. 2017. "Disparities in Breastfeeding: Impact on Maternal and Child Health Outcomes and Costs." Journal of Pediatrics. 181:49-55e6. https://doi.org/10.1016/j.jpeds.2016.10.028 
Binns, Colin, and Mi Kyung Lee. 2019. "Public Health Impact of Breastfeeding." Global Public Health. November. https://doi.org/10.1093/acrefore/9780190632366.013.66

BPAS. 2017. Breastfeeding and Formula Feeding. British Pregnancy Advisory Service. https://www.bpas.org/get-involved/advocacy/briefings/breastfeeding-and-formulafeeding/

Brink, Susan. 2018. "Why the Breastfeeding vs Formula Debate is Especially Critical in Poor Countries." National Public Radio. July 13. https://www.npr.org/sections/goatsandsoda/2018/07/13/628105632/is-infant-formulaever-a-good-option-in-poor-countries

Caron, Christina. 2018. "Breastfeeding or Formula? For Americans, It's Complicated.” New York Times. July 14. https://www.nytimes.com/2018/07/14/health/trump-breastfeedinghistory-nyt.html

Chang, Ashley. 2019. "Bottled Milk: A Mother's Reach for Infant Health.” Natural Library of Medicine. October 26. https://circulatingnow.nlm.nih.gov/2019/09/26/bottled-milk-amothers-reach-for-infant-health/?eType=EmailBlastContent\&eId=6e451877-f4f3-4c2e9a08-d97860712775

Greiner, Ted. 2014. "Exclusive Breastfeeding: Measurement and Indicators." International Breastfeeding Journal. 9:18. https://doi.org/10.1186/1746-4358-9-18

Gupta, Arun, and Shoba Suri. 2016. Has Your Nation Done Enough to Bridge the Gaps? World Breastfeeding Trends Initiative (WBTi). Breastfeeding Promotion Network of India (BPNI)/IBFAN Asia. http://worldbreastfeedingtrends.org/WBTi-84Country/84-countryreport.pdf

Gupta, Arun, Shoba Suri, J. P. Dadhich, Marta Trejos, and Barbara Nalubanga. 2018. "The World Breastfeeding Trends Initiative: Implementation of the Global Strategy for Infant and Young Child Feeding in 84 countries." Journal of Public Health Policy. 40:35-65 https://doi.org/10.1057/s41271-018-0153-9

Gupta, Arun, Barbara Nalubanga, Marta Trejos, J. P. Dadhich, and Nupur Bidla. 2020. Making a Difference: An Evaluation Report of the World Breastfeeding Trends Initiative (WBTi) in Mobilising National Actions on Breastfeeding and IYCF. WBTI, IBFAN, and BPNI. https://www.worldbreastfeedingtrends.org/resources/publications

Haiek, Laura N., Michelle LeDrew, Christiane Charette, and Melissa Bartick. 2021. "Shared Decision-making for Infant Feeding and Care During the Coronavirus Disease 2019 Pandemic." Maternal and Child Nutrition. e13129. DOI: 10.1111/mcn.13129

Hausman, Bernice L. 2008. "Women's Liberation and the Rhetoric of 'Choice' in Infant Feeding Debates." International Breastfeeding Journal. 3:1. 
$\underline{\text { https://internationalbreastfeedingjournal.biomedcentral.com/articles/10.1186/1746-4358- }}$ $\underline{3-10}$

Horii, Naoko, Oumarou Habi, Alio Dangana, Abdou Maina, Souleymane Alzouma, and Yves Charbit. 2016. "Community-based Behavior Change Promoting Child Health Care: A Response to Socio-economic Disparity." Journal of Health, Population and Nutrition. 35:12. DOI 10.1186/s41043-016-0048-y

Horii, Naoko, James Allman, Yves Martin-Prével, and Dominique Waltisperger. 2017. "Determinants of Early Initiation of Breastfeeding in Rural Niger: Cross-sectional Study of Community Based Child Healthcare Promotion." International Breastfeeding Journal. $12: 41$. https://internationalbreastfeedingjournal.biomedcentral.com/articles/10.1186/s13006$\underline{017-0134-9}$

IBFAN. 2019. International Baby Food Action Network. https://www.ibfan.org/

---. 2020. Marketing of Breast Milk Substitutes: National Implementation of the International Code, Status Report 2020. Geneva: World Health Organization. https://www.who.int/publications-detail/9789240006010

Ip, Stanley, Mei Chung, Gowri Raman, Priscilla Chew, Nombulelo Magula, Deirdre DeVine, Thomas Trikalinos, Joseph Lau, 2007. Breastfeeding and Maternal and Infant Health Outcomes in Developed Countries. Rockville, Maryland: Agency for Healthcare Research and Quality. U.S. Department of Health and Human Services. https://archive.ahrq.gov/downloads/pub/evidence/pdf/brfout/brfout.pdf Or https://pubmed.ncbi.nlm.nih.gov/17764214/

Israel-Ballard, Kiersten, et al. 2019. "Call to Action for Equitable Access to Human Milk for Vulnerable Infants.” The Lancet: Global Health. 7(211):E1484-1486. https://www.thelancet.com/journals/langlo/article/PIIS2214-109X(19)30402$\underline{4 / \text { fulltext\#\%20 }}$

Jama, Ngcwalisa Amanda, Aurene Wilford, Zandile Masango, Lyn Haskins, Anna Coutsoudis, Lenore Spies, and Christiane Horwood. 2017. "Enablers and Barriers to Success Among Mothers Planning to Exclusively Breastfeed for Six Months: A Qualitative Prospective Cohort Study in KwaZulu-Natal, South Africa." International Breastfeeding Journal. 12:43. https://doi.org/10.1186/s13006-017-0135-8

Joseph, Friday Ilop, and Jane Earland. 2019. “A Qualitative Exploration of the Sociocultural Determinants of Exclusive Breastfeeding Practices Among Rural Mothers, North West Nigeria." International Breastfeeding Journal. 14:38. https://internationalbreastfeedingjournal.biomedcentral.com/articles/10.1186/s13006019-0231-Z 
Joshi, Prakash Chandra, Mirak Raj Angdembe, Sumon Kumar Das, Shahnawaz Ahmed, AbuSyed Golam Faruque, and Tahmeed Ahmed. 2014. "Prevalence of Exclusive Breastfeeding and Associated Factors Among Mothers in Rural Bangladesh: A Crosssectional Study." International Breastfeeding Journal. 9:7. https://internationalbreastfeedingjournal.biomedcentral.com/articles/10.1186/1746-43589-7

Kent, George. 2005. "HIV/AIDS, Infant Feeding, and Human Rights." In Wenche Barth Eide and Uwe Kracht, eds., Food and Human Rights in Development. Volume I. Legal and Institutional Dimensions and Selected Topics. Antwerp, Belgium: Intersentia. https://www.academia.edu/33199712/HIV AIDS Infant Feeding and Human Rights. 2005

---. 2013. “Questionable Impact of Fatty Acid Supplementation of Infant Formula. In response to Ahmad Qawasmi, Angeli Landeros-Weisenberger, and Michael H. Bloch, Review Article: Meta-analysis of LCPUFA Supplementation of Infant Formula and Visual Acuity." Pediatrics. 131(1):e262-e272. https://doi.org/10.1542/peds.2012-0517

---, 2014 "Regulating Fatty Acids in Infant Formula: Critical Assessment of U.S. Policies and Practices.” International Breastfeeding Journal. 9:2. https://internationalbreastfeedingjournal.biomedcentral.com/articles/10.1186/1746-4358$\underline{9-2}$

---. 2015. "Global Infant Formula: Monitoring and Regulating the Impacts to Protect Human Health.” International Breastfeeding Journal. 10:6. DOI: 10.1186/s13006-014-0020-7

---. 2017a. "Extending the Reach of Human Milk Banking." World Nutrition. 8(2):232-250. https://worldnutritionjournal.org/index.php/wn/article/view/143/111

---. 2017b. Governments Push Infant Formula. Sparsnäs, Sweden: Irene Publishing.

Kramer, Michael S., and Ritsuko Kakuma. 2002. The Optimal Duration of Exclusive Breastfeeding: A Systematic Review." Geneva: World Health Organization. http://www.who.int/nutrition/topics/optimal_duration_of_exc_bfeeding_review_eng.pdf

Lauer, Jeremy A, Ana Pilar Betrán, Aluisio J. D. Barros, and Mercedes de Onís. 2006. "Deaths and Years of Life Lost Due to Suboptimal Breast-feeding Among Children in the Developing World: A Global Ecological Risk Assessment.” Public Health Nutrition. 9(6):673-685. DOI: 10.1079/PHN2005891

Li, Jia, Tuan T. Nguyen, Ifan Duan, Roger Mathisen, and Zhenyu Wang. 2021. "Advice to Use Infant formula and Free Samples are Common in Both Urban and Rural Areas in China: A Cross-sectional Survey." Public Health Nutrition. January 8, pp. 1-12. doi: $10.1017 / \mathrm{S} 1368980020005364$ 
Lowen, Linda 2020. "The History and Definition of Wet Nurse.” Thought Co. https://www.thoughtco.com/history-and-definition-of-wet-nurse-3534100

Mata, Leonardo. 1978. The Children of Santa María Cauqué. A Prospective Field Study of Growth and Health. Cambridge Massachusetts: MIT Press. https://ccp.ucr.ac.cr/bvp/pdf/salud/mata.pdf

McFadden, Alison, Frances Mason, Jean Baker, France Begin, Fiona Dykes, Laurence Grummer-Strawn, Natalie Kenney-Muir, Heather Whitford, Mary J Renfrew. 2016. "Spotlight on Infant Formula: Coordinated Global Action Needed." The Lancet. 387:(10017):413-415. https://doi.org/10.1016/S0140-6736(16)00103-3

Morrell, Erica. 2017. "First Food Justice: Infant Feeding Disparities and the First Food System." Breastfeeding Medicine. 12(8):1-4. https://doi.org/10.1089/bfm.2017.0088

Munblit, Daniel, Helen Crawley, Richard Hyde, and Robert J. Boyle. 2020. "Health and Nutrition Claims for Infant Formula are Poorly Substantiated and Potentially Harmful." BMJ. 369:m875. https://doi.org/10.1136/bmj.m875

Obinna, Chioma. 2017. "Nigerian Mothers Denying Babies Exclusive Breastfeeding." Nigeria Today. August 8. http://www.nigeriatoday.ng/2017/08/nigerian-mothers-denying-babiesexclusive-breastfeeding/

Ogbo, Felix Akpojene, Kingsley E. Agho, and Andrew Page. 2015. "Determinants of Suboptimal Breastfeeding Practices in Nigeria: Evidence From the 2008 Demographic and Health Survey." BMC Public Health. 25:259. DOI 10.1186/s12889-015-1595-7

Ogbo, Felix Akpojene, Mansi Vijaybhai Dhami, Akorede O. Awosemo, Bolajoko O. Olusanya, Jacob Olusanya3, Uchechukwu L. Osuagwu, Pramesh Raj Ghimire, Andrew Page, and Kingsley E. Agho. 2019. "Regional Prevalence and Determinants of Exclusive Breastfeeding in India." International Breastfeeding Journal. 14:20. https://doi.org/10.1186/s13006-019-0214-0

Packard, Vernal S. 1982. Human Milk and Infant Formula. New York: Academic Press.

Paynter, Ben. 2017. Can Encouraging Breastfeeding Around the World Boost the Global Economy? Fast Company. August 1. https:/www.fastcompany.com/40445871/canencouraging-breastfeeding-around-the-world-boost-the-global-economy

Rothstein, Jessica D., Peter J. Winch, Jessica Pachas, Lilia Z. Cabrera, Mayra Ochoa, Robert H. Gilman, and Laura E. Caulfield. 2021. "Vulnerable Families and Costly Formula: A Qualitative Exploration of Infant Formula Purchasing Among Peri-urban Peruvian Households." International Breastfeeding Journal. 16:11 https://doi.org/10.1186/s13006$\underline{021-00356-6}$ 
Rujumba, Joseph, et al. 2020. “'If I Have Money, I Cannot Allow my Baby to Breastfeed Only' Barriers and Facilitators to Scale-up of Peer Counselling for Exclusive Breastfeeding in Uganda.” International Breastfeeding Journal. 15:43. https://doi.org/10.1186/s13006$\underline{020-00287-8}$

Save the Children. 2018. Don't Push it: Why the Formula Industry Must Clean Up Its Act. London: Save the Children Fund. https://www.savethechildren.org.uk/content/dam/gb/reports/health/dont-pushit.pdf?Source $\% 20$ Code $=\&$ cid $=$ esm--bms 001 5R44428VW\&utm campaign=bms 001\&utm medium=earnedsocial\&utm source

Smith, H.A, and G. E. Becker. 2016. "Early Additional Foods and Fluids for Healthy Breastfed Infants." Cochrane Database Systematic Reviews. 8:CD006462. doi: 10.1002/14651858.CD006462.pub4.

UNICEF. 2019a. Infant and Young Child Feeding. New York: United Nations Children's Fund. https://data.unicef.org/topic/nutrition/infant-and-young-child-feeding/

---. 2019b. Only 3 Out of Every 10 Babies Under Six Months Exclusively Breastfed in West and Central Africa, Water the Main Barrier. New York: United Nations Children's Fund. https://www.unicef.org/wca/press-releases/only-3-out-every-10-babies-under-six-monthsexclusively-breastfed-west-and-central

Van Esterik, Penny, and Richard A. O'Connor. 2017. The Dance of Nurture: Negotiating Infant Feeding. New York: Berghahn Books.

Victora, Cesar, Rajiv Bahl, Aluísio J. D. Barros, Giovanny V. A. França, Susan Horton, Julia Krasevec, Simon Murch, Mari Jeeva Sankar, Neff Walker, and Nigel Rollins for The Lancet Breastfeeding Series Group. 2016. "Breastfeeding in the $21{ }^{\text {st }}$ Century: Epidemiology, Mechanisms, and Lifelong Effect." The Lancet. 387(10017):475-490. https://www.thelancet.com/journals/lancet/article/PIIS0140-6736(15)01024-7/fulltext

Vinje, Kristine Hansen. 2017. "SMedia Audit Reveals Inappropriate Promotion of Products Under the Scope of the International Code of Marketing of Breast-milk Substitutes in South-East Asia." Public Health Nutrition. 20(8):1333-1342. doi: $10.1017 / \mathrm{S} 1368980016003591$

WABA. 2012. 21 Dangers of Infant Formula. Penang, Malaysia: World Alliance for Breastfeeding Action. http://www.waba.org.my/whatwedo/advocacy/pdf/21dangers.pdf

Walters, Dylan D., Linh T. H. Phan, and Roger Mathisen. 2019. "The Cost of Not Breastfeeding: Global Results from a New Tool." Health Policy and Planning. 34(6):407-417. https://academic.oup.com/heapol/article/34/6/407/5522499?eType=EmailBlastContent\&e $\underline{\mathrm{Id}=6 \mathrm{e} 451877-\mathrm{f} 4 \mathrm{f3}-4 \mathrm{c} 2 \mathrm{e}-9 \mathrm{a} 08-\mathrm{d} 97860712775 \# 163628322}$

WBTi. 2019. World Breastfeeding Trends Initiative. http://worldbreastfeedingtrends.org/ 
WHO. 2017. Infant and Young Child Feeding. Geneva: World Health Organization. http://www.who. int/mediacentre/factsheets/fs342/en/

---. 2019. Global Breastfeeding Collective. Geneva: World Health Organization. https://www.who.int/nutrition/topics/global-breastfeedingcollective/en/https://journals.sagepub.com/doi/10.1177/089033449601200102

WHO. 2021. Call for authors - Systematic Reviews on Feeding of Infants and Young Children 623 Months of age (2nd set). World Health Organization. https://www.who.int/newsroom/articles-detail/call-for-authors-systematic-reviews-on-feeding-of-infants-andyoung-children-6-23-months-of-age-2set

Wiessinger, Diane. 1996 “Watch Your Language! Journal of Human Lactation. 12(1):1-4. https://www.google.com/url?sa=t\&rct=j\&q=\&esrc=s\&source=web\&cd=\&cad=rja\&uact $=$ $\underline{8 \& v e d=2 \text { ahUKEwjFrI3HicfuAhXTHzQIHZtDCCAQFjABegQIBBAC\&url }=\mathrm{https} \% 3 \mathrm{~A} \%}$ 2F\%2Fjournals.sagepub.com\%2Fdoi\%2Fpdf\%2F10.1177\%2F089033449601200102\&us $\mathrm{g}=\mathrm{AOvV}$ aw3NItE0yf9B16tjb21heASx

Woldeamanuel, Berhanu Teshome. 2020. "Trends and Factors Associated to Early Initiation of Breastfeeding, Exclusive Breastfeeding and Duration of Breastfeeding in Ethiopia: Evidence from the Ethiopia Demographic and Health Survey 2016." International Breastfeeding Journal. 15:3. https://doi.org/10.1186/s13006-019-0248-3 